

\title{
Analysis of Flow Instabilities on a Three-Bladed Axial Inducer in Fixed and Rotating Frames
}

\author{
Giovanni Pace, Dario Valentini, Angelo Pasini, Ruzbeh Hadavandi, Luca
}

D'agostino

\section{- To cite this version:}

Giovanni Pace, Dario Valentini, Angelo Pasini, Ruzbeh Hadavandi, Luca D'agostino. Analysis of Flow Instabilities on a Three-Bladed Axial Inducer in Fixed and Rotating Frames. 17th International Symposium on Transport Phenomena and Dynamics of Rotating Machinery (ISROMAC2017), Dec 2017, Maui, United States. hal-02981013

\section{HAL Id: hal-02981013 \\ https://hal.science/hal-02981013}

Submitted on 27 Oct 2020

HAL is a multi-disciplinary open access archive for the deposit and dissemination of scientific research documents, whether they are published or not. The documents may come from teaching and research institutions in France or abroad, or from public or private research centers.
L'archive ouverte pluridisciplinaire HAL, est destinée au dépôt et à la diffusion de documents scientifiques de niveau recherche, publiés ou non, émanant des établissements d'enseignement et de recherche français ou étrangers, des laboratoires publics ou privés. 


\title{
Analysis of Flow Instabilities on a Three-Bladed Axial Inducer in Fixed and Rotating Frames
}

\author{
Giovanni Pace ${ }^{1 *}$, Dario Valentini ${ }^{1}$, Angelo Pasini ${ }^{2}$, Ruzbeh Hadavandi ${ }^{1}$, Luca d'Agostino ${ }^{2}$

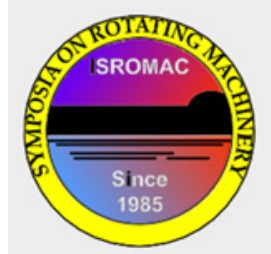 \\ ISROMAC 2017 \\ International \\ Symposium on \\ Transport \\ Phenomena and \\ Dynamics of \\ Rotating Machinery \\ Hawaii, Maui \\ December 16-21 \\ 2017
}

\section{Introduction}

Turbopump-fed rocket engines represent the most weight-effective solution for launch propulsion systems of modern space vehicles that make use of large amounts of liquid propellants. In these applications the turbopumps are required to develop both the high head and superior suction performance necessary to supply the propellant stored in low-pressure, light-weight tanks to the engine's combustion devices that operate at very high pressures. These machines must therefore meet demanding operational requirements and represent a critical (and expensive) component of the rocket propulsion system.

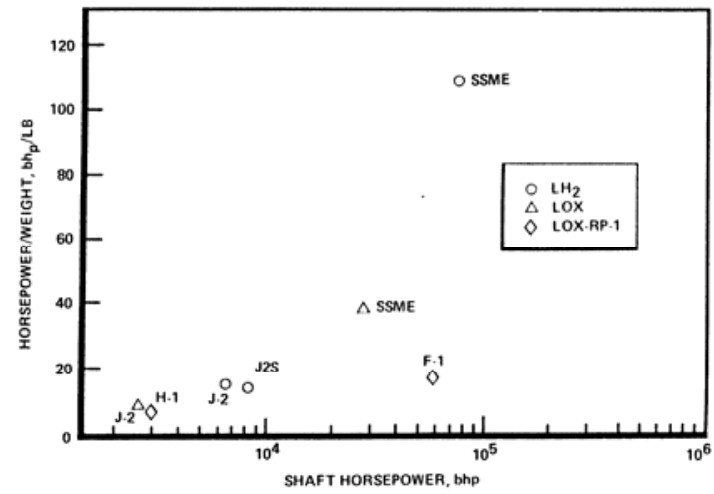

Figure 1. Power/weight evolution of propellant feed turbopumps for US space rocket engines (Rockwell International, personal communication)

Figure 1 shows the evolution of the power/weight ratio of the main propellant feed turbopumps used by US space rocket engines powering the Mercury, Gemini, Apollo and Space Shuttle programs in the two decades from the early '60s to the '80s. The five-fold increase of the power density clearly indicates that today's rocket propellant feed turbopumps belong to a special family of machines with respect to earlier more conventional land, sea-based and even space applications.

Mixed-flow axial inducers are widely used in rocket engines upstream of the main centrifugal stage(s) for increasing the suction performance of propellant feed turbopumps ([19]). Besides, inducer operation under partial cavitation conditions is usually tolerated in order to further reduce the pressurization of propellant tanks and minimize their mass. However, the occurrence of cavitation can often be responsible for the onset of undesirable flow phenomena limiting the suction performance, efficiency, power density, reliability and useful life of rocket propellant feed turbopumps ([31], [32], [29]). In modern tapered-hub inducers the combination of high blade solidity, low inlet flow incidence and the contribution of centrifugal effects to the head generation effectively reduces the blade loads and improves the suction performance of the machine for given pressure rise. At the same time, the occurrence of cavitation at the entrance and, under higher blade loads, also inside the blade channels promotes the development of selfsustained resonant flow instabilities ([30], [28], [20], [5], [6], [21], [3], [16], [1], [2], [7], [8], [34], [24]).

Flow-induced instabilities of turbopumps originate from a number of interaction mechanisms and can be conveniently classified as proposed by Brennen [4] in:

- global oscillations (including surge, cavitation autooscillations, rotating stall, rotating cavitation, unsteady partial-blade and vortex cavitation, higher order 
cavitation surge) affecting the whole machine or even the entire pumping system on a large scale;

- local oscillations of more limited extent (like blade flutter and rotor-stator interactions);

- rotordynamic instabilities caused by unsteady fluid forces acting on the impellers.

According to a different yet useful classification proposed by Franc [15], flow-induced instabilities of turbopumps can be divided in:

- system instabilities, also involving the other components of the pumping system (inlet and outlet lines, tanks, valves),

and:

- intrinsic instabilities, whose extent is limited to the flow through the machine.

The main types of tubopump flow instabilities have recently been reviewed by d'Agostino [13]. For a general introduction to cavitation instabilities and flow-induced rotordynamic effects in turbopumps the reader is referred to the monograph by d'Agostino and Salvetti [14].

The present work illustrates the results of a series of experiments recently conducted by the authors in their Cavitating Pump Rotordynamic Test Facility (CPRTF) with the aim of characterizing the flow instabilities on a threebladed inducer, named RAPDUD, operating at different flow coefficients under non-cavitating/cavitating conditions. Following a well-established approach ([7], [8], [34], [24]), spectral analysis and correlation of the pressure perturbations generated by the inducer flow instabilities has been used to detect their occurrence and identify their nature. More specifically, present experiments focused on refining the characterization of the cavitation phenomena developing inside the inducer blade channels and their interactions with the flow instabilities occurring in the impeller eye. Earlier experiments to this purpose, like those carried out by Yoshida and his collaborators ([38], [39], [40]), suitably multiplexed at the frequency of the impeller rotation the measurements of pressure transducers flush-mounted on the impeller casing in order to extract the information on the flow behavior in the blade channels. A peculiar aspect of present experiments is that the pressure transducers have been mounted both on the casing and on the hub of the inducer, in order to allow for the simultaneous analysis of the flow instabilities in the stationary and rotating reference frames. Earlier tests by Fujii ([18]) made use of transducers placed at the trailing edge of the inducer blades, where they can be more easily installed. Here the pressure taps of the hub-mounted transducers have been located at several stations along the midline of the blade channels from the leading to the trailing edges of the blades for better investigating the nature and behavior of the flow instabilities developing or extending deep inside the impeller.

\section{Experimental Set-Up and Procedure}

The Cavitating Pump Rotordynamic Test Facility (Figure 2) is a versatile and easily instrumentable water loop operating at temperatures up to $90{ }^{\circ} \mathrm{C}$, in order to adequately scale thermal cavitation effects developing when pumping most cryogenic space propellants ([27], [22]). The facility is intended as a flexible apparatus that can readily be adapted to conduct experimental investigations on virtually any kind of fluid dynamic phenomena relevant to high performance turbopumps in a wide variety of alternative configurations (axial, radial or mixed flow pumps and their combination: centrifugal stage and inducer ([9], [33], [34], [26], [23], [24], [25], [36] , [37] , [17]).

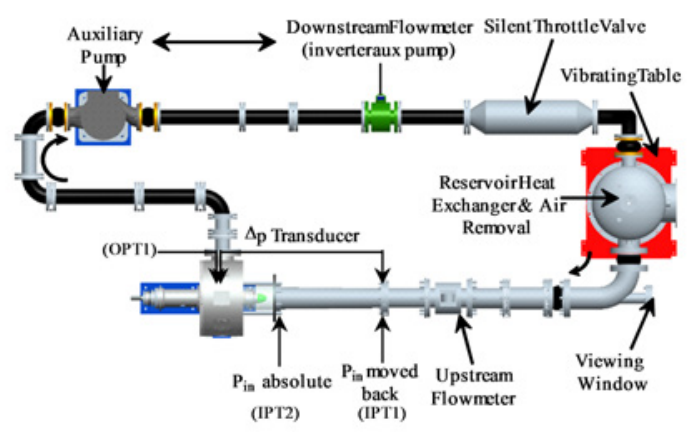

Figure 2. The Cavitating Pump Rotordynamic Test Facility.

The CPRTF equipment includes an air bag, an electrical heater and a silent throttle valve in order to adjust the pump inlet pressure, water temperature and flow rate, respectively. The rotational speed can be continuously varied from 0 to $3000 \mathrm{rpm}$ by means of a 30 kW brushless, digitally controlled electrical motor. The facility allows for carrying out tests under Euler, Reynolds and thermal cavitation similarity conditions by exploiting the possibility of reducing the rotational speed in model tests without significantly interfering with the scaling of turbulent flow phenomena occurring in the machine prototypes that typically operate at Reynolds numbers in the $10^{7}-10^{8}$ range. An alternative CPRTF configuration has been especially designed for the experimental analysis of radial and rotordynamic forces exerted by the flow on turbopump impellers and inducers ([22]).

In present experiments the facility has been instrumented as necessary for characterizing the flow instabilities of the RAPDUD inducer, as well as its pumping and suction performance. The test section has been equipped with a Plexiglas casing for lateral optical access to the inducer flow. The inducer casing has been instrumented with piezoelectric pressure transducers (PCB Piezotronics, model S112A22). Eight of them have been flush-mounted on the Plexiglas casing at different axial and azimuthal positions. At each axial station the duct can host up to five transducers with $45^{\circ}$ relative angular spacing (Figure 3) for phase and coherence cross-correlation analyses of their signals. In the following the position of each PCB transducer on the inlet duct is designated by an acronym, such as for example SF1\#0 . The first number identifies the axial station (1,2 or 3 ) in the flow direction. The last number identifies the angular 
clockwise spacing in degrees from the uppermost pressure tap (see Figure 3).

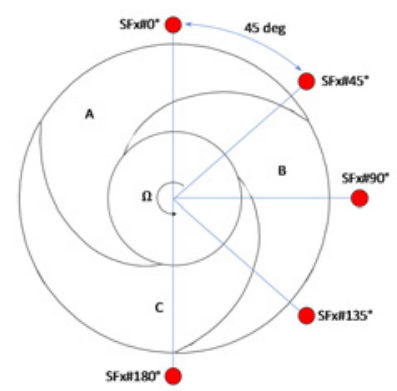

Figure 3. The Pressure taps position for inlet duct and blades channels names.

Waterfall plots of the power spectral densities of the pressure fluctuations at different cavitation numbers have been used to detect the presence of flow instabilities at the operation conditions of interest. The axial or azimuthal nature of each instability and, in the second case, the number of rotating cells involved have been identified by cross-correlating the pressure signals from two transducers mounted with known azimuthal spacing at the inlet station of the inducer.

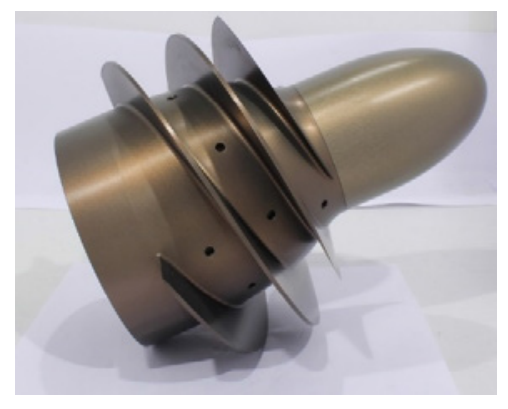

Figure 4. The RAPDUD inducer with the pressure taps on the hub.

In the present experimental campaign, piezoresistive pressure transducers (Kulite model XTM-190M) have been flush-mounted on the inducer hub (Figure 4) in order to measure the absolute pressure of the flow rather than its unsteady fluctuation as in the case of piezoelectric transducers. Spectral techniques similar to those used for stationary pressure transducers have been used to analyze the signals of hub-mounted transducers and compare the results obtained in both cases.

For maximum flexibility five pressure taps have been located on the inducer hub along each blade channel, as shown in Figure 5.

The vertical dashed line indicates the beginning of the fully developed portion of the inducer blades and is used in Table 1 for specifying the position of each pressure tap relative to the chord length measured along the hub. Specifically, each pressure transducer is identified by means of an acronym where the letters $A, B$ or $C$ refer to the first, second and third blade channel (Figure 3) and the numbers indicate the position of the pressure tap relative to the blade chord (Figure 5).

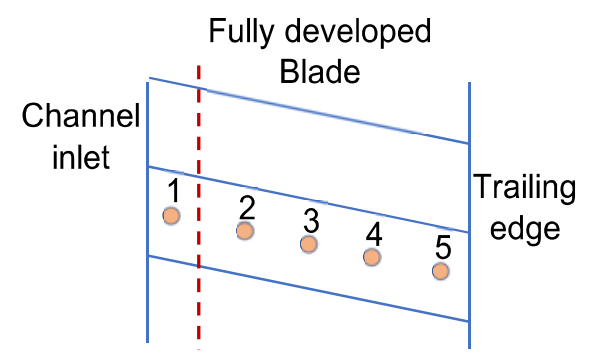

Figure 5. Location of the pressure taps along the blade channels.

The operating conditions for the hub-mounted transducers are very demanding as they can be exposed to the high pressures generated by cavitation collapse in the blade channels and are also subject to intense centrifugal accelerations (up to $700 \mathrm{~g}$ at $3000 \mathrm{rpm}$ for the transducers positioned at the largest distance from the rotational axis). The main characteristics of the employed transducers are reported in Table 2.

Table 1 Position of the pressure taps along the inducer hub.

\begin{tabular}{ccc}
\hline Pressure tap & Ax [\% of chord] & Radius [mm] \\
\hline 1 & -22.2 & 38.56 \\
\hline 2 & 26.5 & 51.3 \\
\hline 3 & 41.6 & 53.2 \\
\hline 4 & 58.5 & 55.7 \\
\hline 5 & 72.2 & 57.0 \\
\hline
\end{tabular}

In addition, the test equipment (see Figure 2) includes:

- two electromagnetic flowmeters (Fisher-Rosemount, model $8732 \mathrm{E}$, range: $0-100 \mathrm{l} / \mathrm{s}$, accuracy $0.5 \% \mathrm{FS}$ ), for the measurement of the inlet and outlet flow rates;

- two absolute pressure transducers placed one (IPT2) and six (IPT1) diameters upstream of the blade leading edge (GE, model Druck PMP1400, range 0 $\div 1$ bar, accuracy $0.25 \%$ FS; GE, model UNIK5000, range $0 \div 2$ bar, accuracy $0.1 \% \mathrm{FS}$ ), for the evaluation of the cavitation number;

Table 2 Main characteristics of the Kulite XTM-190M and PCB S112A22 transducers.

\begin{tabular}{ccc}
\hline Transducer & Kulite & PCB Piezotronics \\
\hline Model & XTM-190M & S112A22 \\
\hline Technology & Piezoresistive & Piezoelectric \\
\hline Pressure Range, bar & $0 \div 3.5$ & $0 \div 3.45$ \\
\hline Sensitivity, V/bar & 0.01 & 1.45 \\
\hline Resolution, $\mathrm{kPa}$ & Infinitesimal & 0.007 \\
\hline Temperature Range, ${ }^{\circ} \mathrm{C}$ & $-29 \div 175$ & $-73 \div 135$ \\
\hline Natural Frequency, $\mathrm{kHz}$ & 95 & 250 \\
\hline $\begin{array}{c}\text { Combined Non-Linearity, } \\
\text { Hysteresis and Repeatability }\end{array}$ & $\pm 1 \% \mathrm{FS}$ & $\leq 1 \% \mathrm{FS}$ \\
\hline
\end{tabular}

- two differential pressure transducers for the measurement of the inducer pressure rise between the inlet stations located one (IPT2/OPT1) and six 
(IPT1/OPT1) diameters upstream of the blade leading edges and the outlet station located about one diameter downstream of the blade trailing edges (GE, model UNIK5000, range $0 \div 1$ bar, accuracy $0.1 \%$ FS; GE, model UNIK5000, range $0 \div 5$ bar, accuracy $0.1 \%$ FS);

- one temperature sensor (PT100, range $0 \div 100{ }^{\circ} \mathrm{C}$, accuracy $0.5^{\circ} \mathrm{C}$ );

- $\quad$ one photocamera and one high-speed videocamera for the visualization of the cavitating flow in the inducer.

Table 3 Main geometrical and operational parameters of the RAPDUD inducer.

\begin{tabular}{|c|c|c|}
\hline Inducer Name & Symbol & RAPDUD \\
\hline Material & & AL7075-T6 \\
\hline Blade Number & $N$ & 3 \\
\hline Inlet Tip Radius, mm & $r_{T i}$ & 81 \\
\hline Outlet Tip Radius, mm & $r_{T o}$ & 81 \\
\hline Inlet Tip Blade Angle, ${ }^{\circ}$ & $\gamma_{T l e}$ & 82.8 \\
\hline Outlet Tip Blade Angle, ${ }^{\circ}$ & $\gamma_{T t e}$ & 79.65 \\
\hline $\begin{array}{l}\text { Inlet Hub Radius, mm } \\
\text { (Fully-Developed Blade) }\end{array}$ & $r_{H l e}$ & 45 \\
\hline Outlet Hub Radius, mm & $r_{H t e}$ & 58.5 \\
\hline $\begin{array}{c}\text { Axial Length, mm } \\
\text { (Fully-Developed Blade) }\end{array}$ & $c_{a}$ & 69 \\
\hline Tip Solidity & $\sigma_{T}$ & 2.276 \\
\hline Design Flow Coefficient & $\Phi_{D}$ & 0.070 \\
\hline Design Rotational Speed, rpm & $\Omega_{D}$ & 1500 \\
\hline Geometrical Inlet Hub Radius, mm & $r_{H i}$ & 35 \\
\hline Overall Axial Length, mm & $L$ & 90 \\
\hline Clearance, $\mathrm{mm}$ & $c_{l e}$ & 0.8 \\
\hline Mean Blade Height, mm & $h_{m}$ & 29.25 \\
\hline
\end{tabular}

The RAPDUD inducer tested in the present campaign is a three-bladed, high-head, axial inducer with tapered hub and variable pitch. It has been designed to given suction and pumping performance requirements by means of the reduced order model recently developed by d'Agostino and his collaborators ([11], [12]). Its characteristics are reported in Table 3.

Finally, the configuration of the RAPDUD inducer test section is illustrated in Figure 6.

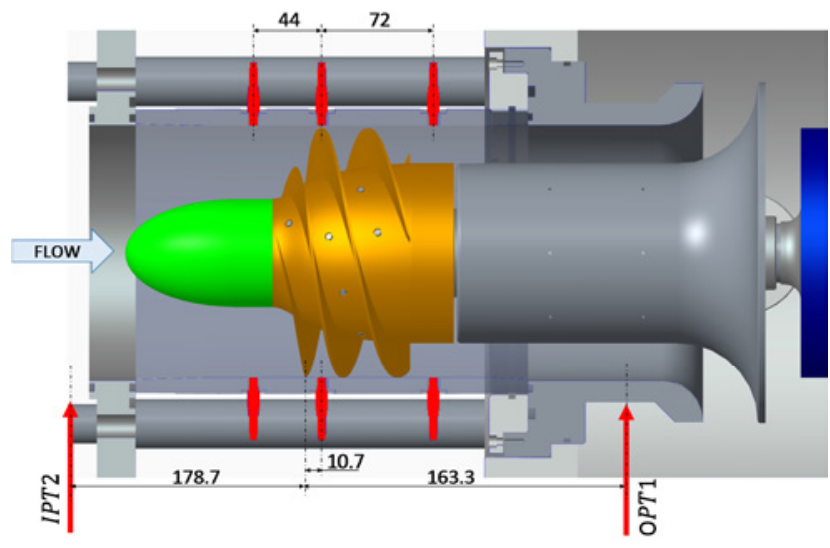

Figure 6. Test section configuration of the RAPDUD inducer (dimensions in $\mathrm{mm}$ ).

\section{Results and Discussion}

A series of characterization tests at room temperature $\left(T=20^{\circ} \mathrm{C}\right)$ and two different rotating speeds $(\Omega=1500$ and $2000 \mathrm{rpm}$ ) has been carried out for determining the non-cavitating pumping performance of the RAPDUD inducer in terms of the relevant dimensionless parameters:

- Head Coefficient: $\Psi=\Delta p / \rho \Omega^{2} r_{T}^{2}$

- Flow Coefficient: $\Phi=Q / \pi \Omega r_{T}^{3}$

- Reynolds Number: $\operatorname{Re}=2 \Omega r_{T}^{2} / v$

- Cavitation Number: $\quad \sigma=2\left(p_{i n}-p_{v}\right) / \rho \Omega^{2} r_{T}^{2}$

where $\Delta p$ is the inducer static pressure rise, $\rho$ is the flow density, $\Omega$ the rotational speed, $r_{T}$ the inducer tip radius, $v$ the kinematic viscosity of the flow, $p_{\text {in }}$ the inducer inlet pressure and $p_{v}$ the vapor pressure.

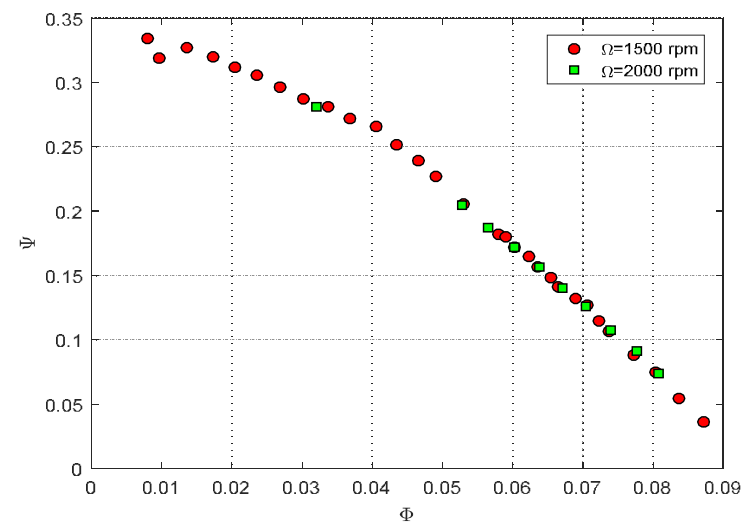

Figure 7. Non-cavitating pumping characteristic of the RAPDUD inducer $\left(T=20^{\circ} \mathrm{C}\right)$.

The static pressure rise has been measured between IPT1 and OPT1 stations and cavitation in the inducer flow has been suppressed by properly adjusting the inlet pressure (and therefore the Euler number) well above the inception conditions. The results are illustrated in Figure 7 where the dimensionless head characteristics measured at the two rotating speeds are shown. Their overlap confirms the expected Reynolds independence of the 
experimental results for the fully turbulent flow developing in the inducer under the tested conditions.

A second series of characterization tests has been carried out at room temperature $\left(T=20^{\circ} \mathrm{C}\right)$ and rotating speed $\Omega=3000 \mathrm{rpm}$ for determining the suction performance of the RAPDUD inducer. The static pressure rise has been measured between the IPT1 and OPT1 stations at different values of the inducer inlet pressure above and below the inception conditions, while the flow has been kept constant by means of a servo-actuated auxiliary control pump installed on the inducer discharge line. Both steady-state and quasi-steady tests have been conducted in order to experimentally determine the inducer suction performance. In steady-state tests the inlet pressure and flow rate are kept constant during the measurement of the corresponding head rise. Conversely, in quasi-steady tests the inlet pressure is slowly and continuously decreased from non-cavitating conditions to breakdown (or possibly to the most intense cavitating conditions compatible with the capabilities of the test facility). The measurements have been acquired over $10 \mathrm{~s}$ and $240 \mathrm{~s}$ for the steady-state and quasi-steady tests, respectively, in both cases at the same rate of 5000 samples per second.

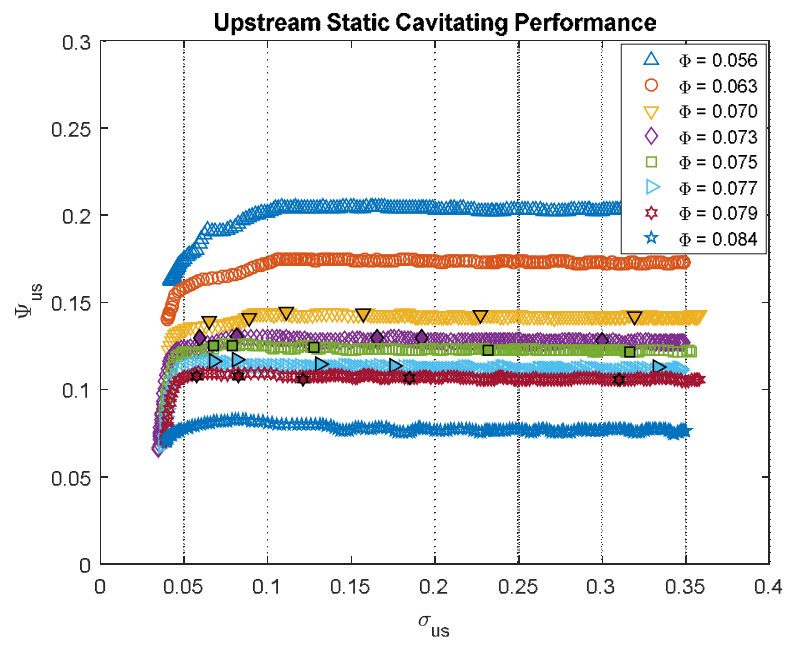

Figure 8. Suction characteristic of the RAPDUD inducer at $\mathrm{T}=$ $20^{\circ} \mathrm{C}, \Omega=3000 \mathrm{rpm}$ and the indicated values of the flow coefficient.

The results are illustrated in Figure 8 where the dimensionless suction characteristics measured for the indicated values of the flow coefficient are shown. The overlap of the steady-state data points on the continuous curve of the quasi-steady tests confirms the accuracy of the two acquisition methods.

The pressure signals measured under inducer cavitation conditions by the statoric (PCB) and rotating transducers (Kulite) have been spectrally analyzed as in previous CPRTF experiments $([9,[33],[24])$ for detecting and identifying the occurrence and the nature of cavitation-induced flow instabilities.

Table 4 Flow instabilities detected in the RAPDUD inducer in the statoric reference frame.

\begin{tabular}{|c|c|c|c|c|c|}
\hline $\begin{array}{l}\text { Instability } \\
\text { I.D. }\end{array}$ & $\begin{array}{c}\text { Frequency } \\
{[\mathrm{Hz}]}\end{array}$ & $\frac{\Phi}{\Phi_{D}}$ & $\begin{array}{l}\mathrm{x} \text { : yes } \\
-: \text { no }\end{array}$ & $\begin{array}{l}\text { Range } \\
\quad \sigma\end{array}$ & Characteristics \\
\hline \multirow{3}{*}{ A1 } & & 0.80 & - & & \multirow{3}{*}{ Axial } \\
\hline & $8.85-14.3$ & 1.00 & $x$ & $0.08-0.05$ & \\
\hline & $18.3-4.8$ & 1.20 & $x$ & $0.13-0.05$ & \\
\hline \multirow{3}{*}{$\mathrm{RC} 1$} & $23.2-20.7$ & 0.80 & $\bar{x}$ & $0.05-0.04$ & \multirow{3}{*}{1 Cell } \\
\hline & & 1.00 & - & & \\
\hline & & 1.20 & - & & \\
\hline \multirow{3}{*}{ A2 } & & 0.80 & - & & \multirow{3}{*}{ Axial } \\
\hline & & 1.00 & - & & \\
\hline & $23.2-19.2$ & 1.20 & $x$ & $0.34-0.24$ & \\
\hline \multirow{3}{*}{$\mathrm{RC} 2$} & $46.7-40.9$ & 0.80 & $x$ & $0.10-0.07$ & \multirow{3}{*}{1 Cell } \\
\hline & $41.2-35.4$ & 1.00 & $\mathrm{x}$ & $0.08-0.04$ & \\
\hline & & 1.20 & - & & \\
\hline \multirow{3}{*}{ A3 } & & 0.80 & - & & \multirow{3}{*}{ Axial } \\
\hline & & 1.00 & - & & \\
\hline & $54.6-55$ & 1.20 & $\mathrm{x}$ & $0.32-0.12$ & \\
\hline \multirow{3}{*}{ A4 } & & 0.80 & - & & \multirow{3}{*}{ Axial } \\
\hline & & 1.00 & - & & \\
\hline & $76.9-74.7$ & 1.20 & $\mathrm{x}$ & $0.11-0.08$ & \\
\hline \multirow{3}{*}{ RC3 } & $92-81$ & 0.80 & $x$ & $0.10-0.07$ & \multirow{3}{*}{2 Cell } \\
\hline & $82.4-71.7$ & 1.00 & $x$ & $0.08-0.05$ & \\
\hline & & 1.20 & - & & \\
\hline \multirow{3}{*}{ RC4 } & $103.1-110$ & 0.80 & $x$ & $0.10-0.05$ & \multirow{3}{*}{2 Cell } \\
\hline & $\begin{array}{c}109.6- \\
114.4\end{array}$ & 1.00 & $x$ & $0.08-0.05$ & \\
\hline & & 1.20 & - & & \\
\hline \multirow{3}{*}{ A5 } & $110.1-115$ & 0.80 & $\mathrm{x}$ & $0.34-0.17$ & \multirow{3}{*}{ Axial } \\
\hline & & 1.00 & - & & \\
\hline & & 1.20 & - & & \\
\hline \multirow{3}{*}{ RC5 } & & 0.80 & - & & \multirow{3}{*}{1 Cell } \\
\hline & & 1.00 & - & & \\
\hline & 253 & 1.20 & $x$ & $0.04-0.03$ & \\
\hline \multirow{3}{*}{ A6 } & & 0.80 & - & & \multirow{3}{*}{ Axial } \\
\hline & & 1.00 & - & & \\
\hline & 364 & 1.20 & $\mathrm{x}$ & $0.34-0.18$ & \\
\hline
\end{tabular}

Fast Fourier transforms have been used to compute the auto-correlations, cross-correlations and coherence functions of the pressure signals. The peaks of the autocorrelation spectra indicate the occurrence, frequency and relative intensity of the inducer flow instabilities. At each frequency of interest the corresponding phases of the cross-correlations of the signals from two transducers with known spatial separation allow for discrimination of the axial or rotating nature of the flow instabilities, as well as for identification of the number of cells involved in their propagation. Finally, the statistical significance of the results is assessed from the value of the coherence function at the frequency of the instability under consideration. 
Analysis of Flow Instabilities on a Three-Bladed Axial Inducer in Fixed and Rotating Frame - 6
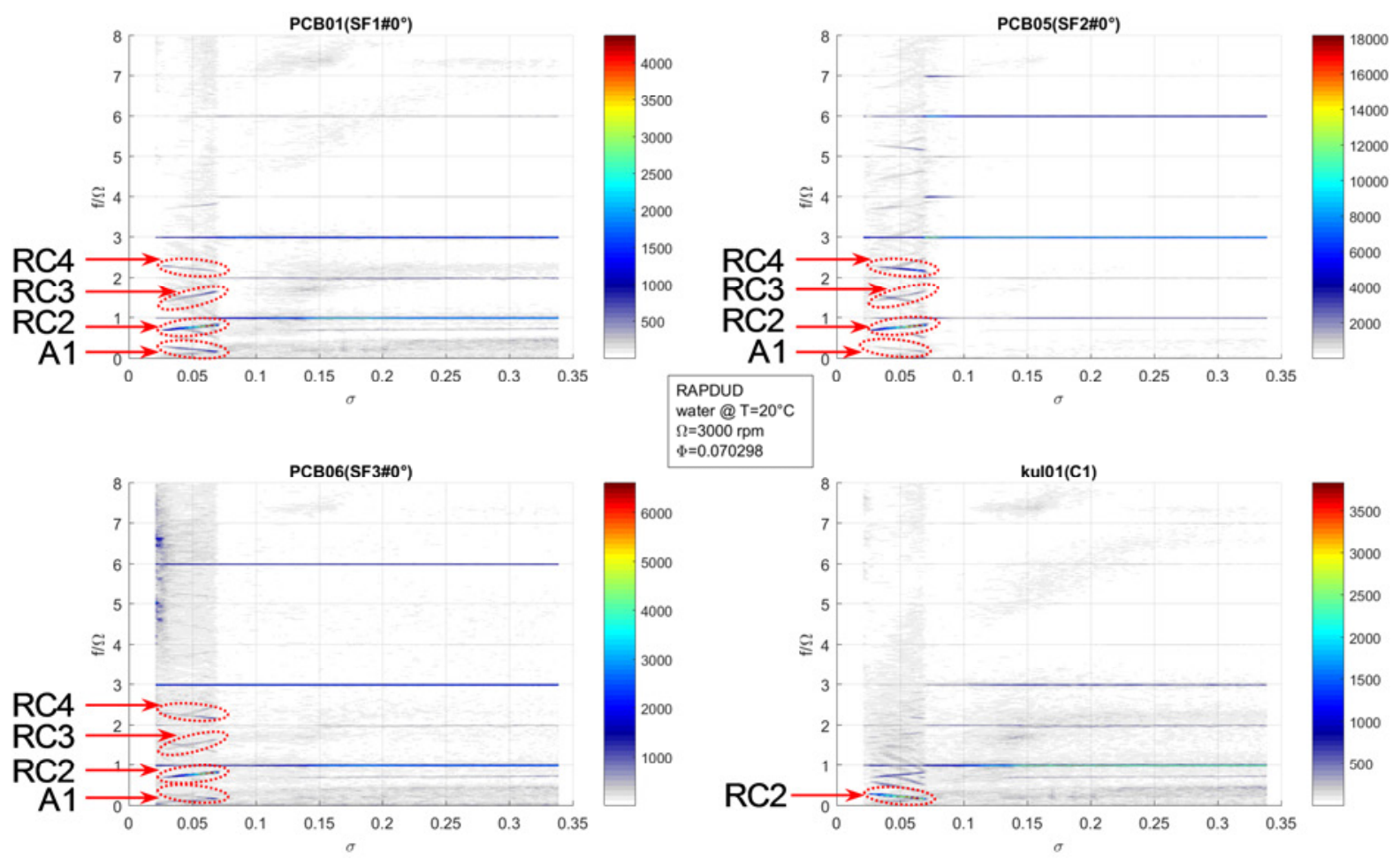

Figure 9. Spectra of the pressure oscillations amplitude for $\Phi=\Phi_{D}$ and $T=20^{\circ} \mathrm{C}$ measured in Pascal by the specified transducers mounted in the stationary and rotating frames.
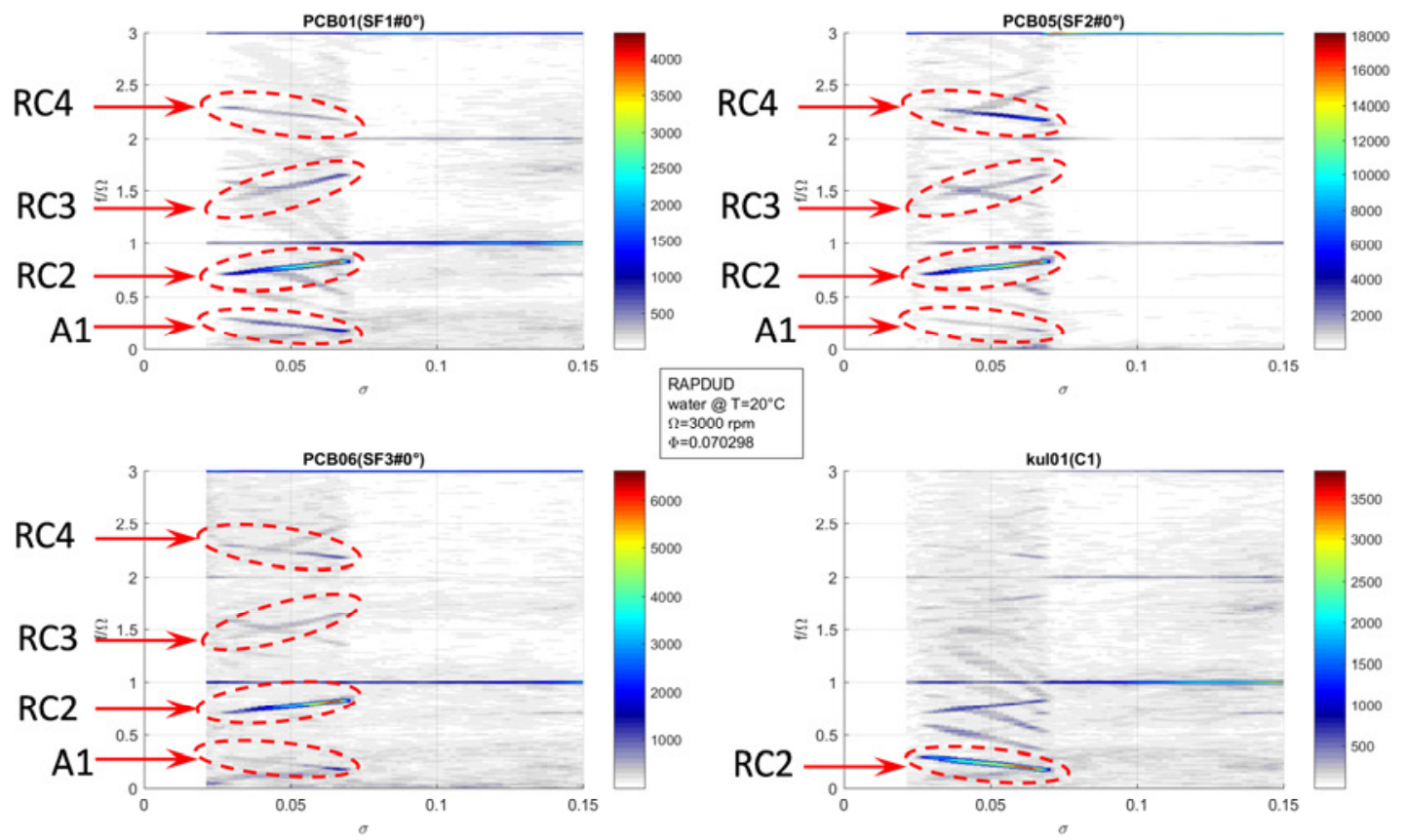

Figure 10. Enlargement of the spectra of pressure oscillations amplitude shown in Figure 9.

In particular, axial phenomena are characterized by zero phase of the pressure cross-spectra, while the crossspectral phases of rotating phenomena are proportional to the circumferential spacing $\Delta \theta$ between the sensing transducers and to the number $n$ of lobes of the phenomenon. Aliasing can be eliminated, for phenomena involving up to four cells in the azimuthal direction, by comparing the cross-correlations of pressure signals from transducers with different angular separations. The crosscorrelation phase of flow instabilities co-rotating (counterrotating) with the pump motion increases (decreases) with the azimuthal separation of the sensing transducers. 
Hence, for example, the cross-correlation phase of a single-cell, co-rotating/counter-rotating instability is $\pm 45^{\circ}$ when computed from the signals of two transducers with an azimuthal separation of $45^{\circ}$. The analysis is validated by checking the value of the coherence function $\gamma_{x y}$ between signals obtained from different transducers pairs. Here, only phenomena with $\gamma_{x y}$ values considerably greater than 0.8 have been taken in consideration.

The data reported in this article refer to the operation of the RAPDUD inducer at $80 \%, 100 \%$ and $120 \%$ of the design flow coefficient (even though the analysis has been carried out over a larger number of flow rate conditions). Flow instabilities have first been detected using the signals from the stationary PCBs mounted on the casing at the inlet station of the inducer. Next, the analysis has been extended to the signals of the hub-mounted transducers for comparison and better interpretation of the results.

As an example of the above analysis, Figure 9 shows the spectra of the pressure oscillations measured by the PCBs mounted at three different axial stations on the inducer casing. The flow instabilities detected from these spectra are listed in Table 4. Figure 9 also shows the corresponding pressure spectra obtained from the hubmounted Kulite transducer located at the entrance of the third inducer blade channel (C). In Figure 10 an enlargement of the power spectra is shown for the most interesting region of cavitation number and frequency.

As is clearly noticeable, all the transducers detect the $\mathrm{RC} 2$ phenomenon, which is recognized as a single-cell rotating instability whose frequency is shifted in the rotating system by $-\Omega$. The RC2 phenomenon co-rotates


Figure 11 Cross-correlation phase in degrees of the pressure transducers on the statoric (top) and rotating (bottom left) frames, together with the dimensionless suction performance (bottom right) for $\Phi=\Phi_{D}$ and $T=20^{\circ} \mathrm{C}$. The vertical lines (continuous and long-dashed) refer to the beginning and the end of the RC2 and RC1 flow oscillations. 

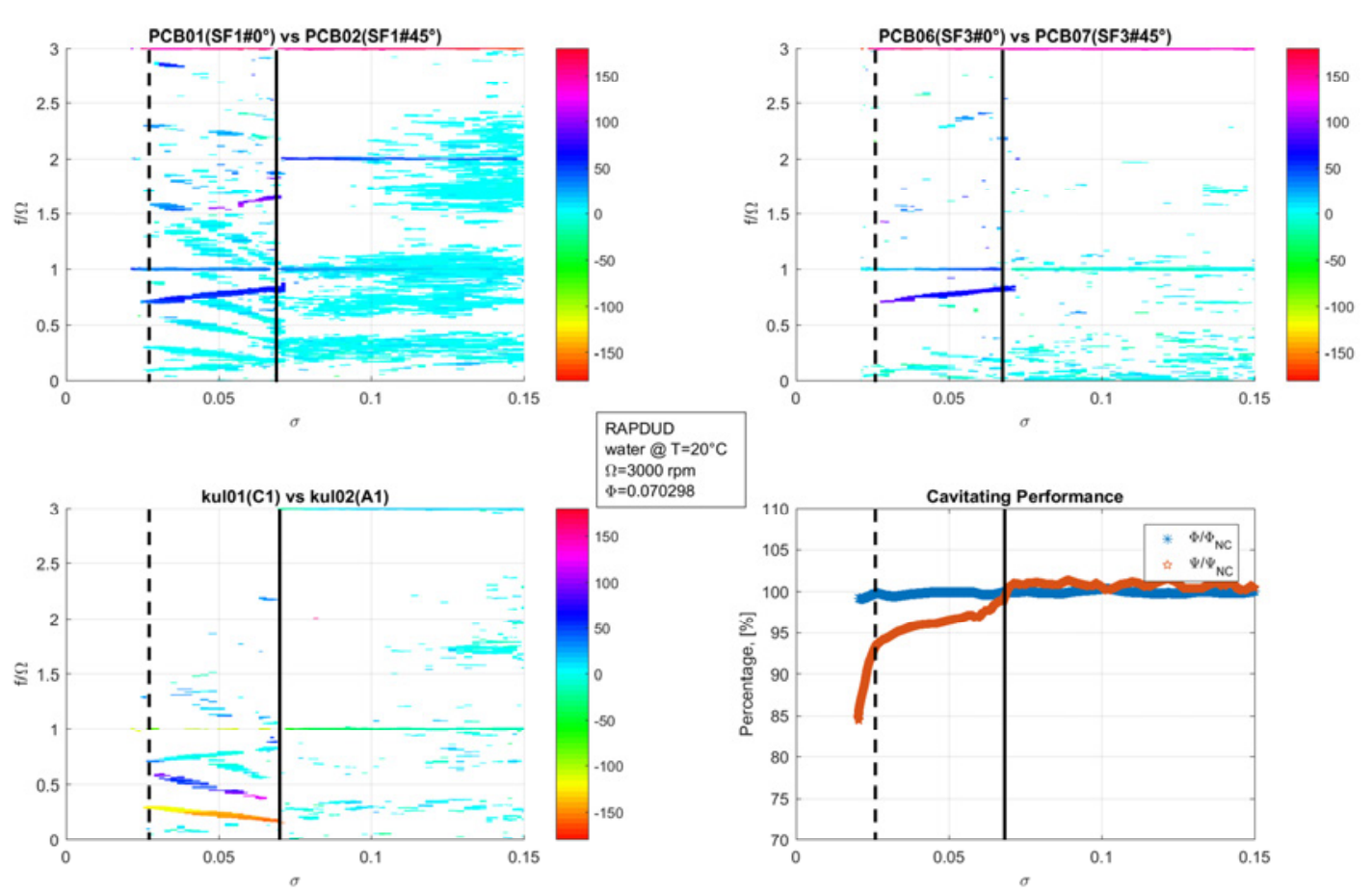

Figure 12 Enlargement of the cross-correlation phase depicted in Figure 11.

The analysis of the figure leads to conclusions consistent with the results previously illustrated in Table 4 concerning the nature of the instabilities occurring in the test inducer.

It is, for instance, possible to confirm that the phenomenon RC2 consists if a single-cell rotating instability, as the cross-correlation phase of the PCBs signals in the stationary frame is equal to the azimuthal angular separation of the sensing transducer pairs $\left(45^{\circ}\right)$. The same holds true also in the rotating frame, where the azimuthal angular displacement between the sensing transducers is $120^{\circ}$ and the cross-correlation phase between the signals is about $-120^{\circ}$, which confirms the counter-rotating nature of the phenomenon as seen in the impeller frame.

The two vertical lines in Figure 11 identify the range of cavitation numbers $\sigma$ where the RC2 phenomenon occurs. It is of interest to notice that the cavitation performance of the inducer undergoes a first step-like drop at inception of the RC2 instability. This feature is consistent with the results obtained by many investigators, including earlier experiments by some of the authors, for inducers subject to the onset of rotating cavitation conditions ([33], [10],
[24]). During the further development of the flow oscillation at lower cavitation numbers the inducer head continues to decrease in a more regular fashion, until the RC2 instability disappears. At this point the pump head undergoes a second step-like drop, which drives the pump to cavitation breakdown. The occurrence of the RC2 instability detected by stationary transducers in the inducer eye provides a periodic excitation of the flow at the entrance of the inducer blade channels, with shifted frequency when observed in the rotating frame. It is therefore plausible to that the cavitating flow in the inducer blades responds to this excitation by developing oscillations propagating along the blade channels at the shifted frequency. Earlier results also support the presence of the dynamic coupling between the RC2 instability in the rotating frame and the occurrence at the same frequency of the A1 axial oscillation of the inlet flow to the inducer. It appears therefore that the first drop of the suction performance of the test inducer might actually be caused by the combined effects of the RC2 and A1 instabilities, which together represent an important source of blade lift reduction and flow dissipation consistent with the observed behavior of the inducer suction performance. 



Figure 13. Cross-correlation phase in degrees of the pressure transducers on the statoric (top) and rotating (bottom left) frames, together with the dimensionless suction performance (bottom right) for $\Phi=0.8 \Phi_{D}$ and $T=20^{\circ} \mathrm{C}$. The vertical lines (continuous, dashed and long-dashed) refer to the beginning and the end of the RC2 and RC1 flow oscillations.

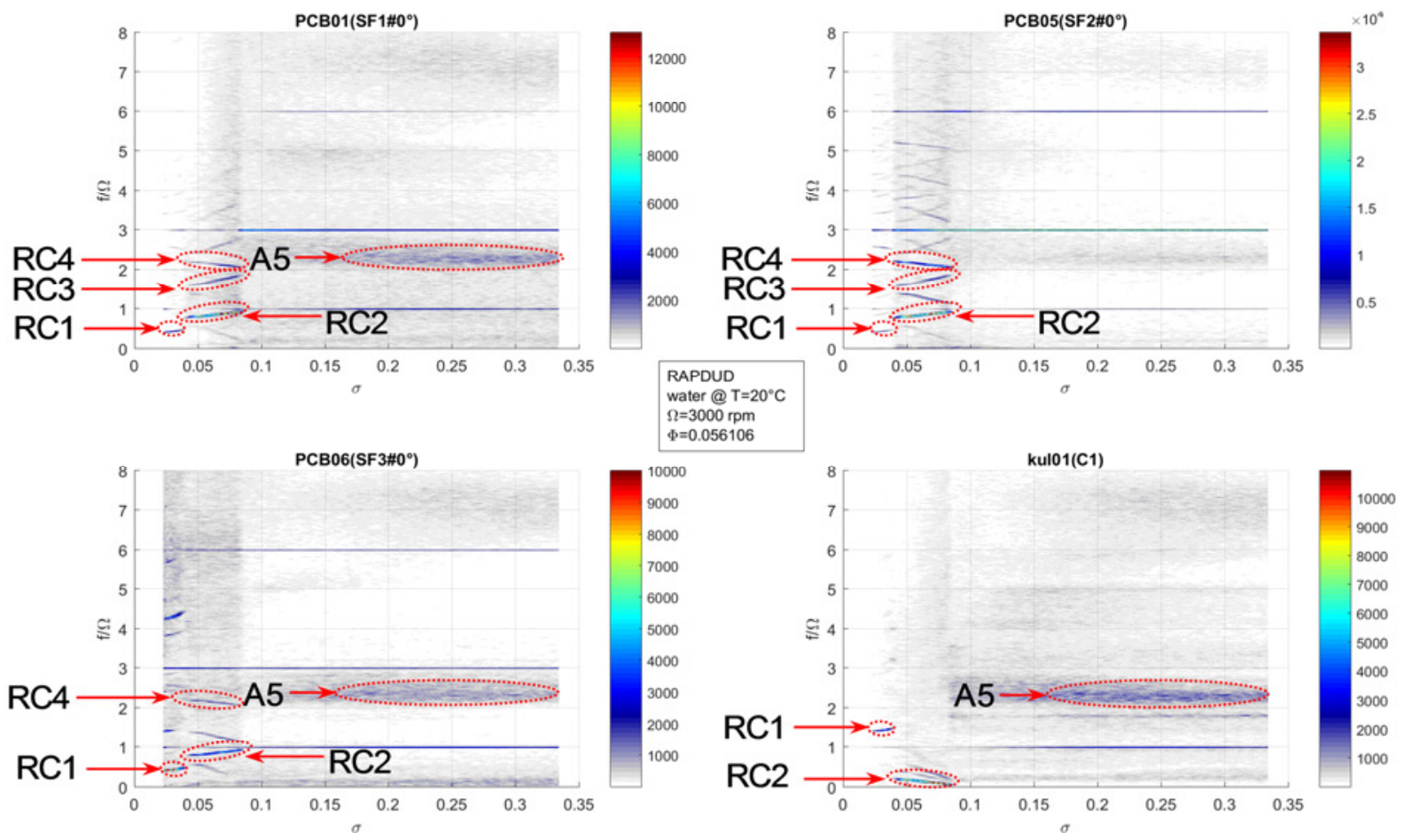

Figure 14. Spectra of the pressure oscillations amplitude for $\Phi=0.8 \Phi_{D}$ and $T=20^{\circ} \mathrm{C}$ measured in Pascal at the mounting stations of the indicated transducers.

Similar conclusions can also be drawn from the results of the cross-correlation experiments illustrated in Figure 13 for inducer operation at a lower flow rate $\left(\Phi=0.8 \Phi_{D}\right)$. The main difference of interest with respect to the case of design flow conditions is the evidence of a new rotating phenomenon (RC1), which develops at very low cavitation numbers (just lower than for the RC2 oscillation) and is responsible of the second step-like drop of the inducer suction performance. Besides, the experimental results indicate that at this reduced flow rate the first head drop 
due to rotating cavitation is less intense than at design flow conditions.

Figure 14 shows the spectra of the pressure oscillation amplitudes measured at different axial stations in the statoric and rotating frames, together with the indication of the main flow instabilities detected by the analysis of the data. As expected, the frequency of axial flow oscillations is unchanged in the rotating frame, whereas the frequency of rotating phenomena is shifted by $\pm \Omega$. Both the RC1 and $\mathrm{RC} 2$ are sub-synchronous, but RC2 is shifted in the fixed frame by $+\Omega$ because it is counter-rotating. Even if additional pressure oscillations are recognizable, only the most relevant phenomena have been highlighted in the figure.
Figure 15 illustrates the cross-correlation phase obtained for inducer operation at $\Phi=1.2 \Phi_{D}$. The results of these experiments at increased flow rate indicate the absence of important rotating instabilities at low cavitation numbers and frequencies as a consequence of the reduction of the blade load, especially in the proximity of the leading edges. While at higher flow rates most rotating cavitation phenomena have disappeared in the moderately sub- and super-synchronous portion of the spectrum, low-amplitude axial and rotating instabilities are still present at higher frequencies. Among these, a singlecell rotating cavitation mode can be observed at very high frequencies (RC5), as well as a low-amplitude (lower than $100 \mathrm{~Pa})$, high-frequency axial oscillation (A6).
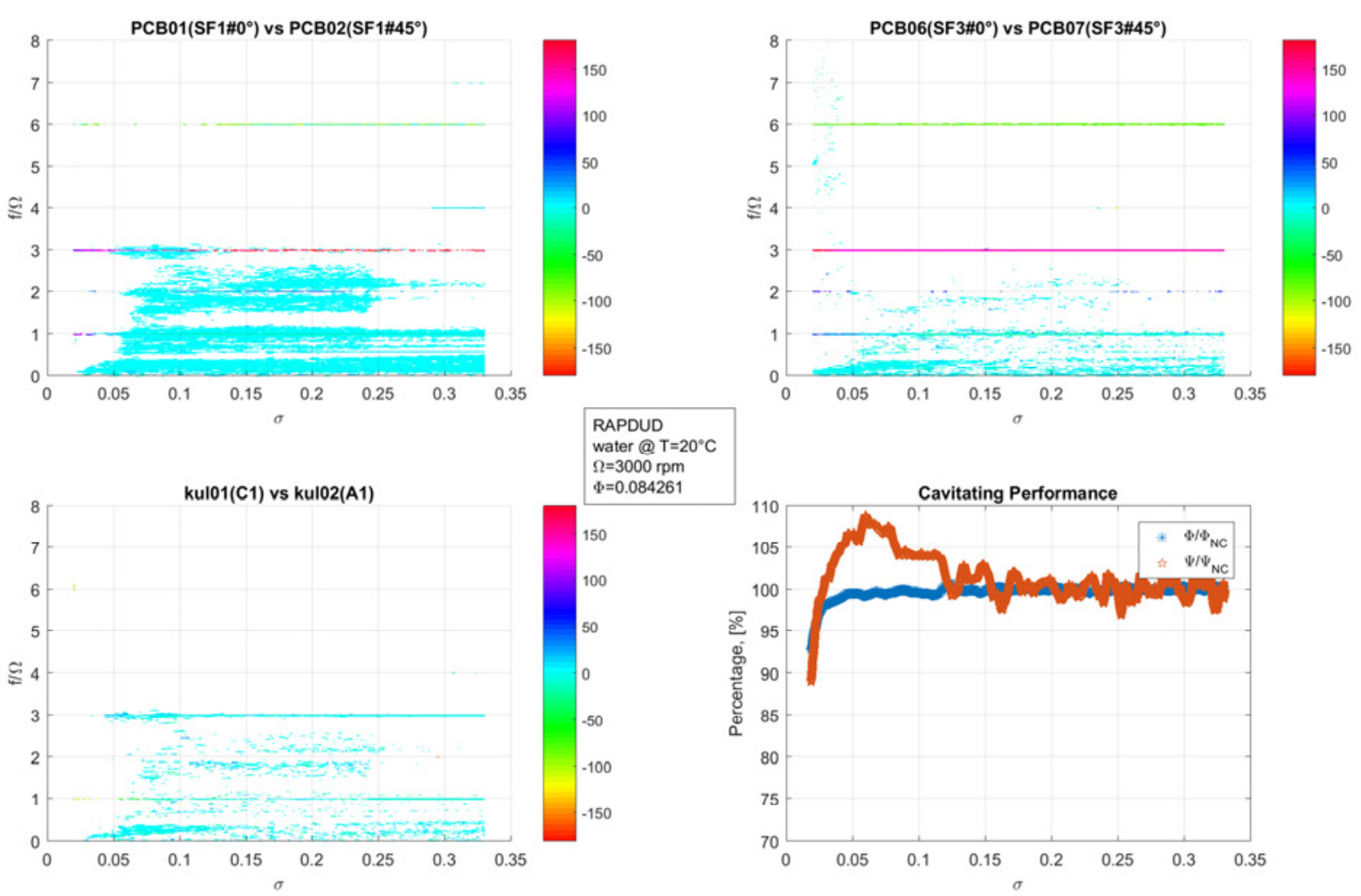

Figure 15. Cross-correlation phase in degrees of the pressure transducers on the statoric (top) and rotating (bottom left) frames, together with the dimensionless suction performance (bottom right) for $\Phi=1.2 \Phi_{D}$ and $T=20^{\circ} \mathrm{C}$ 

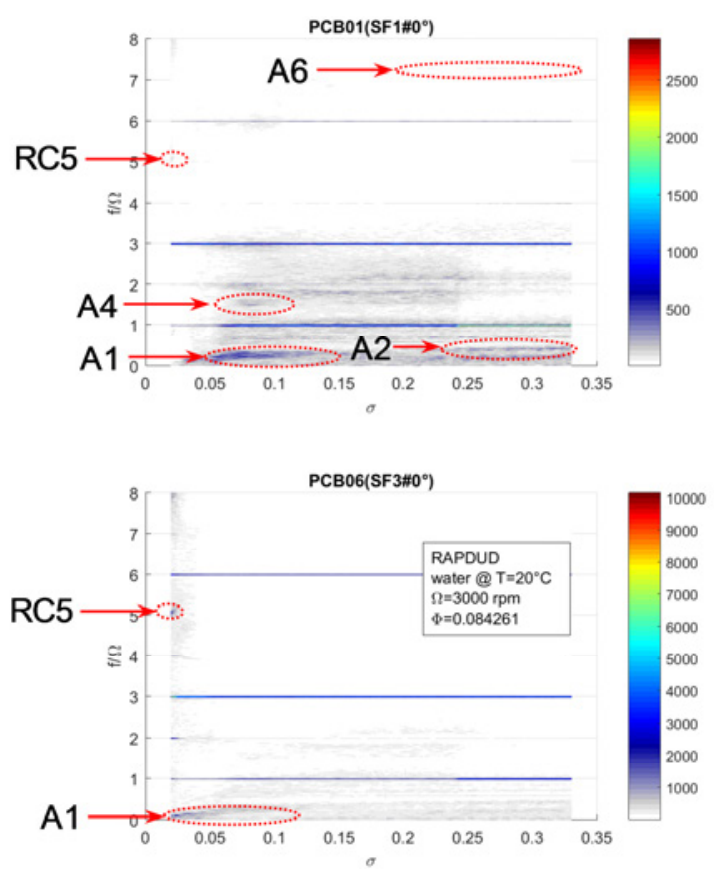


Figure 16. Spectra of the pressure oscillations amplitude for $\Phi=1.2 \Phi_{D}$ and $T=20^{\circ} \mathrm{C}$ measured in Pascal at the mounting stations of the indicated transducers.

A peculiar aspect of the experimental results at flow rates higher than design is the increase of the head under cavitating conditions before flow breakdown, also frequently observed by previous investigators under similar conditions ([7], [34], [35]). It has sometimes been explained as the consequence of the flow rate reduction and blade load increase generated by the head loss induced by cavitation in experiments with fixed throttling of the discharge line. However, contrary to most previous experiments, in the present set-up the flow rate is actively kept constant by the auxiliary pump. Hence, it is plausible to conclude that the observed head rise is actually due to the redistribution of the flow pressure on the suction side of the impeller blades under cavitating conditions. Presumably, at moderate levels of cavitation intensity the leveling of the pressure near the vapor pressure in the upstream portion of the suction side of the blade more than compensates the reduction of the suction peak in the proximity of the leading edge.

\section{Conclusions}

The combined and simultaneous use of casingmounted (stationary) and hub-mounted (rotating) pressure transducers for detecting, identifying and characterizing the flow instabilities occurring in a three-bladed, taperedhub and variable-pitch inducer under noncavitating and cavitating conditions represents a qualifying aspect of present experiments conducted in the CPRTF.

Following a well-established approach, the flow instabilities occurring in the inducer eye have been characterized by cross-correlating the measurements of the piezoelectric pressure transducers installed on the inducer casing. However, virtually no information is obtained in this way on the development and/or propagation of the flow instabilities in the cavitating flow inside the inducer blading. As a natural extension of this approach, the installation of piezoresistive pressure transducers on the inducer hub along the midline of the blade channels and the application of spectral methods to analyse their signals have been implemented in the present research activity and successfully demonstrated their capability to overcome some of the limitations associated with the use of casing-mounted transducers alone.

Hub-mounted piezoresistive transducers sensitive to the static pressure of the flow proved capable of providing novel and more detailed information on the steady and unsteady cavitating flow in the inducer blade channels. The comparison of the spectral behavior of the flow simultaneously observed in the stationary and rotating frames allowed for detecting and characterizing some of the dynamic interactions taking place between the unstable flows in the eye and in the blade channels of cavitating inducers. More specifically, the available evidence indicates that rotating cavitation in the impeller eye, which is observed at a shifted frequency in the rotating frame, is dynamically coupled with the occurrence of synchronous flow oscillations at that frequency along the blade channels. Besides, the spatial resolution provided by the installation of multiple transducers on the inducer hub also allowed to show that the amplitude of these oscillations peaks near the center of the blade channels. This finding is consistent with what is expected for the axial resonant modes of a compressible two-phase flow in open-ended ducts, thus confirming that the observed instabilities of the cavitating flow in inducer 
blade channels are likely due to excitation of internal resonant modes of the flow (higher order surge).

The experimental results also confirmed the role of the onset of rotating cavitation modes in shaping the observed degradation of the suction characteristic of inducers and its dependence on the flow coefficient (i.e. on the blade load). The active stabilization of the flow rate in present experiments also suggests that the observed head increase under incipient cavitating conditions is likely due to the redistribution of the flow pressure on the suction side of the impeller blades associated with the occurrence of cavitation, rather than being the consequence of the flow rate reduction and blade load increase generated by the head loss induced by cavitation in experiments with fixed throttling of the inducer discharge line.

The authors believe that present exploratory experiments can contribute to improving the understanding of the complex flow phenomena and interactions involved in the occurrence and development of cavitation-induced instabilities in modern high-head inducers.

\section{Acknowledgments}

The present work has been possible thanks to the supports of the European Space Agency along several years. The authors would like to express their great gratitude to Dr. Giorgio Saccoccia and Dr. Gianni Pellegrini. Special gratitude goes to Lucio Torre that has been a great mainstay of the whole Chemical Propulsion Team for many years and to Dr. A. Sonaho (now GMYSSpace) for his friendship and constant support.

\section{Nomenclature}

$\begin{array}{cl}\text { Latin } & \\ \boldsymbol{A} & \text { Axial } \\ \boldsymbol{C} & \text { Continuous } \\ \boldsymbol{L} & \text { Overall Axial Length } \\ \boldsymbol{N} & \text { Blade Number } \\ \boldsymbol{Q} & \text { Flow Rate } \\ \boldsymbol{R C} & \text { Rotating Cavitation } \\ \boldsymbol{R} \boldsymbol{e} & \text { Reynolds } \\ \boldsymbol{S} & \text { Steady-State } \\ \boldsymbol{T} & \text { Temperature } \\ \boldsymbol{c} \boldsymbol{a} & \text { Axial Length } \\ \boldsymbol{c l} \boldsymbol{e} & \text { Clearance } \\ \boldsymbol{h} & \text { Blade Height } \\ \boldsymbol{p} & \text { Pressure } \\ \boldsymbol{r} & \text { Radius } \\ \text { Greek } & \\ \boldsymbol{\Delta} & \text { Variation } \\ \boldsymbol{\Phi} & \text { Flow Coefficient } \\ \boldsymbol{\Psi} & \text { Head Coefficient } \\ \boldsymbol{\Omega} & \text { Rotational Speed } \\ \boldsymbol{\gamma} & \text { Blade Angle, Coherence } \\ \boldsymbol{v} & \text { Fluid Kinematic Viscosity } \\ \boldsymbol{\rho} & \text { Fluid Density } \\ \boldsymbol{\sigma} & \text { Solidity } \\ \text { Subscripts } \\ \boldsymbol{D} & \text { Design } \\ & \end{array}$

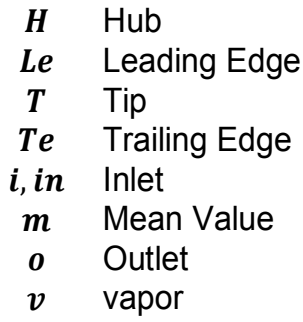

\section{References}

[1] Bhattacharyya A., 1994, "Internal Flows and Force Matrices in Axial Flow Inducers", Ph. D. Thesis, Report no. E249.18, California Institute of Technology, Pasadena, USA.

[2] Bhattacharyya A., Acosta A. J., Brennen C. E., Caughey T. K., 1997, "Rotordynamic Forces in Cavitating Inducers", ASME Journal of Fluids Engineering, 199(4), pp.768-774.

[3] Braisted D. M., 1979, "Cavitation Induced Instabilities Associated with Turbomachines", Report No. E184.2, California Institute of Technology, 1979.

[4] Brennen C. E., 1994, "Hydrodynamics of Pumps", Oxford University Press, Oxford Engineering Science Series 44.

[5] Brennen C.E., Acosta A.J., 1973, "Theoretical, QuasiStatic Analysis of Cavitation Compliance in Turbopumps", J. of Spacecraft, Vol. 10, No. 3, pp. 175179.

[6] Brennen C.E. and Acosta A.J., 1976, "The Dynamic Transfer Function for a Cavitating Inducer", ASME J. Fluids Eng., Vol. 98, pp. 182-191.

[7] Cervone A., Testa R., Bramanti C., Rapposelli E., and d'Agostino L., 2005, "Thermal Effects on Cavitation Instabilities in Helical Inducers", AIAA J. of Propulsion and Power, Vol. 21, No. 5, pp. 893-899.

[8] Cervone A., Torre L., Bramanti C., Rapposelli E, and d'Agostino L., 2006, "Experimental Characterization of Cavitation Instabilities in a Two-Bladed Axial Inducer", AIAA J. of Propulsion and Power, Vol. 22, No. 6, NovDec 2006, pp. 1389-1395.

[9] Cervone A., Torre L., Pasini A., and d'Agostino L., 2009, "Cavitation and Flow Instabilities in a 3- Bladed Axial Inducer Designed by Means of a Reduced Order Analytical Model", Proc. 7th International Symposium on Cavitation, CAV2009 - Paper No. \#92, August 1722, Ann Arbor, Michigan, USA.

[10] Cervone A., Pace G., Torre L., Pasini A., Bartolini S., Agnesi L., d'Agostino L. 2012, "Effects of the Leading Edge Shape on the Performance of an Axial Three Bladed Inducer", 14th Int. Symp. on Transport Phenomena and Dynamics of Rotating Machinery, ISROMAC-14, February 27th - March 2, 2012, Honolulu, HI, USA.

[11] d'Agostino L., Torre L., Pasini A. and Cervone A., 2008a, "A Reduced Order Model for Preliminary Design and Performance Prediction of Tapered Inducers", 12th Int. Symp. on Transport Phenomena and Dynamics of Rotating Machinery (ISROMAC-12), Honolulu, HI, USA, USA, February 17-22. 
[12] d'Agostino L., Torre L., Pasini A., Cervone A., 2008b, "On the Preliminary Design and Noncavitating Performance of Tapered Axial Inducers", ASME J. of Fluids Engineering, Vol. 130, Is. 11, November 2008, pp. 111303-1/111303-8.

[13] d'Agostino L., 2013, "Turbomachinery Developments and Cavitation", STO-AVT-LS-206, Paper NBR 12-1, Invited Lecture, VKI Lecture Series on Fluid Dynamics Associated to Launcher Developments, von Karman Institute of Fluid Dynamics, Rhode-Saint-Genèse, Belgium, April 15-17.

[14] d'Agostino L. and Salvetti M.V. (eds.), 2017, "Cavitation Instabilities and Rotordynamic Effects in Turbopumps and Hydroturbines - Turbopump and Inducer Cavitation, Experiments and Design", CISM International Centre for Mechanical Sciences, Courses and Lectures, Vol. 575 No. 1408, Springer, Vien and [33]New York.

[15] Franc J. P., 2001, "Partial Cavity Instabilities and ReEntrant Jet", CAV2001, Int. Symposium on Cavitation, Pasadena, California, USA, June 20-23.

[16] Franz R. J., 1989, "Experimental Investigation of the Effect of Cavitation on the Rotordynamic Forces on a Whirling Centrifugal Pump Impeller", Ph.D. Thesis, California Institute of Technology, Pasadena, USA.

[17] Fu Y., Yuan J., Yuan S., Pace G. and d'Agostino L., 2017, "Effect of Tip Clearance on the Internal Flow and Hydraulic Performance of a Three-Bladed Inducer", Hindawi, International Journal of Rotating Machinery, Vol. 2017.

[18] Fujii,A., Kawamura, Y., Hidaka, T., Uchiumi, M., Yoshida, Y. and Tsujimoto, Y., 2004, "Higher Order Rotating Cavitation in an Inducer under Head Break Down", 10th International Symposium on Transport Phenomena and Dynamics of Rotating Machinery (ISROMAC-10), Honolulu, Hawaii, USA, 2004.

[19] Jakobsen J.K., 1971, "Liquid Rocket Engine Turbopump Inducers", NASA SP 8052.

[20] Natanzon M. S. et al., 1974, "Experimental Investigation of Cavitation Induced Oscillations of Helical Inducers", Fluid Mech. Soviet Res., Vol. 3 No. 1, pp.38-45.

[21] Ng S.L. and Brennen C.E., 1978, "Experiments on the Dynamic Behavior of Cavitating Pumps", ASME J. Fluids Eng., Vol. 100, No. 2, pp. 166-176.

[22] Pace, G., Pasini, A., Torre, L., Valentini, D. and d'Agostino, L., 2012, "The Cavitating Pump Rotordynamic Test Facility at ALTA S.p.A.: Upgraded Capabilities of a Unique Test Rig", in Space Propulsion Conference, May 7-10, Boredeaux, France, 2012.

[23] Pace G., Valentini D., Torre L., Pasini A., d'Agostino L., 2014, "Experimental Characterization of Rotordynamic Forces Acting on Space Turbopumps", Space Propulsion 2014, May 19-22, Cologne, Germany.

[24] Pace G., Valentini D., Pasini A., Torre L., Fu Y., d'Agostino L., 2015, "Geometry Effects on Flow Instabilities of Different Three-Bladed Inducers", ASME J. Fluids Engineering, Vol. 137(4)/011102-1, 041304, April 01, 2015.

[25] Pace G., Valentini D., Pasini A., Torre L., Hadavandi
R., d'Agostino L., 2016, "Inducer and Centrifugal Pump Contributions to the Rotordynamic Fluid Forces Acting on a Space Turbopump", ISROMAC 2016, International Symposium on Transport Phenomena and Dynamics of Rotating Machinery, Honolulu, Hawaii, USA, April 10-15.

[26] Pasini A., Torre L., Cervone A., d'Agostino L., 2011, "Continuous Spectrum of the Rotordynamic Forces on a Four Bladed Inducer", ASME J. Fluids Eng. Vol. 133, Iss. 12, December 2011.

[27] Rapposelli, E., Cervone, A. and d'Agostino, L., 2002, "A New Cavitating Pump Rotordynamic Test Facility," AIAA Paper 2002-4285, 38th AIAA/ASME/SAE/ASEE Joint Propulsion Conf., Indianapolis, IN, USA, July 811.

[28] Rosenmann W., 1965, "Experimental Investigations of Hydrodynamically Induced Shaft Forces With a Three Bladed Inducer", Proc. ASME Symp. on Cavitation in Fluid Machinery.

[29] S. Rubin, 1966, "Longitudinal Instability of Liquid Rockets Due to Propulsion Feedback (POGO)", Journal of Spacecraft and Rockets, vol. 3, no. 8, pp. 1188-1195.

[30] Sack L. E., Nottage H. B., 1965, "System Oscillations Associated to Cavitating Inducers", ASME J. Basic Eng., Vol. 87, pp. 917-924.

[31] Stripling, L. B. and Acosta, A. J., 1962, "Cavitation in Turbopumps - Part 1", ASME J. Basic Eng, Vol. 84, pp. 326-338.

[32] Stripling, L. B. and Acosta, A. J., 1962, "Cavitation in Turbopumps - Part 2", ASME J. Basic Eng, Vol. 84.

[33] Torre L., Pace G., Miloro P., Pasini A., Cervone A., d'Agostino L., 2010, "Flow Instabilities on a ThreeBladed Axial Inducer at Variable Tip Clearance", 13th Int. Symp. on Transport Phenomena and Dynamics of Rotating Machinery, ISROMAC-13, Honolulu, HI, USA, April 4-9.

[34] Torre L., Cervone A., Pasini A., d'Agostino L., 2011a, "Experimental Characterization of Thermal Cavitation Effects on Space Rocket Axial Inducers", ASME Journal of Fluids Engineering, Vol. 133, Is. 11, November 11, pp. 111303-1, 111303-10.

[35] Torre L., Pasini A., Cervone A., Pace G., Miloro P. and d'Agostino L., 2011b, "Effect of Tip Clearance of the Perfomance of a Three-Bladed Axial Inducer", AIAA Journal of Propulsion and Power, Vol. 27, No. 4, JulAug 2011, pp. 890-898.

[36] Valentini D., Pace G., Pasini A., Torre L., Hadavandi R., d'Agostino L., 2016, "Fluid-Induced Rotordynamic Forces on a Whirling Centrifugal Pump", ISROMAC 2016, International Symposium on Transport Phenomena and Dynamics of Rotating Machinery, Honolulu, Hawaii, USA, April 10-15.

[37] Valentini D., Pace G., Pasini A., Torre L., Hadavandi R., d'Agostino L., 2017, "Fluid-Induced Rotordynamic Forces on a Whirling Centrifugal Pump", European Journal of Mechanics - B/Fluids, Vol. 61, Part 2, pp. 336-345.

[38] Yoshida, Y., Kikuta, K., Watanabe, M., Hashimoto, T., Nagaura, K., Ohira, K., 2006a, "Thermodynamic Effect 
on Cavitation Performances and Cavitation Instabilities in an Inducer", $6^{\text {th }}$ Inte. Symp. on Cavitation, CAV2006, Wageningen, The Netherlands, September 11-15.

[39] Yoshida, Y., Sasao, Y., Okita, K., Hasegawa, S., Shimagaki, M., Nakamura, N., 2006b, "Influence of Thermodynamic Effect on Synchrounous Rotating Cavitation", 6 ${ }^{\text {th }}$ Inte. Symp. on Cavitation, CAV2006, Wageningen, The Netherlands, September 11-15.

[40] Yoshida, Y., Kikuta, K., Hasegawa, S., Shimagaki, M., Nakamura, N., Tokumasu, T., 2006c, "Thermodynamic Effect on a Cavitating Inducer in Liquid Nitrogen", $6^{\text {th }}$ Inte. Symp. on Cavitation, CAV2006, Wageningen, The Netherlands, September 11-15. 